\title{
A aprendizagem através do Funk nas medidas socioeducativas: Relato de experiência realizada no Centro de Atendimento Socioeducativo (CASE) Santa Maria/RS
}

\author{
El aprendizaje a través del Funk en las medidas educativas: relato de la \\ experiencia lograda en el Centro de Atendimento Socioeducativo (CASE) \\ Santa María/RS
}

\author{
The learning through the Funk in The Partner-Educational Measures: \\ Report of the experience accomplished in the center of service socio- \\ educational (CASE) Santa Maria/RS
}

\author{
Alícia de Oliveira Gonçalves ${ }^{1}$ \\ Jane Schumacher ${ }^{2}$
}

\begin{abstract}
Resumo
O Funk é uma das maiores expressões culturais dos estilos de vida e realidade da juventude das periferias brasileiras. Esta juventude na maioria das vezes enfrenta realidades de vulnerabilidade social e violência, o que muitas vezes contribui para o envolvimento desses jovens com o crime. Este artigo discorre sobre o estudo do Funk como processo emancipatório nas medidas socioeducativas do CASE-Santa Maria/RS, e tem como objetivos compreender a importância do Funk como ferramenta de aprendizagem, entender os processos de expressão cultural, política e social dos jovens e contribuir para a eficácia das medidas socioeducativas. Trata-se de uma Pesquisa Qualitativa, utilizando Método de Abordagem Dialético, e como técnica a observação participante através das oficinas do Projeto Leitura, Ação: Dramatização, realizadas no ano de 2018 com jovens em medidas socioeducativa no CASE Santa Maria/RS, no âmbito do convênio entre Universidade Federal de Santa Maria, Ministério Público Estadual e Fundação de Atendimento Socioeducativo. Os resultados observados no desenvolvimento das oficinas foram de reconhecimento dos jovens como sujeitos políticos e sociais e protagonistas da sua história, melhora dos níveis de leitura e construção do conhecimento e reconhecimento do Funk como expressão cultural das suas realidades.
\end{abstract}

Palavras-chave: Cultura; Educação Emancipadora; Funk; Juventude; Medidas Socioeducativas.

\section{Resumen}

El Funk es una de las expresiones culturales más grandes de los estilos de vida y realidad de la juventud de periferias brasileño. Esta juventud enfrenta las realidades de la vulnerabilidad sociable y la violencia la mayor parte del tiempo, que muchas veces aportan a la participación de esos ones jóvenes con el pecado. Este artículo habla del estudio del Funk como proceso emancipatório en las medidas socioeducativas en CASE Santa Maria/RS, y tiene com objetivos comprender la importancia del Funk como herramienta de aprendizaje, entender los procesos de la expresión cultural, la política y social de los jóvenes y aportar para la eficacia de las medidas socioeducativas. Es una investigación cualitativa, mediante el método de abordage Dialetico, y como la técnica la participante observación a través de los talleres del proyecto Investigación, acción: dramatización, consumado en el año de 2018 con jóvenes in medidas socioeducativas en el Case Santa Maria/RS, en la extensión del acuerdo entre Universidade Federal de Santa Maria, Ministerio Publico e Fundación de socioeducativo del atención. Los resultados observaron hacia dentro que el desarrollo de los talleres era del reconocimiento de los jóvenes tan políticas asignaturas sociales y protagonistas suyos / su historia, él se ponen mejores de los niveles

\footnotetext{
${ }^{1}$ Graduanda em Serviço Social pela Universidade Federal de Santa Maria; Brasil; aliciadeoliveirag@ gmail.com

${ }^{2}$ Doutora em Educação pela Universidade Federal do Rio Grande do Sul, Brasil; mixjanepereira@yahoo.com.br
} 
de lectura y los construcción de los conocimientos y reconocimiento del Funk como la expresión cultural de sus realidades.

Palabras claves: Cultura; Educación emancipadora; Funk; Juventud; Medidas socioeducativas.

\begin{abstract}
The Funk is one of the largest cultural expressions of the lifestyles and the youth's of the Brazilian peripheries reality. This youth most of the time faces realities of social vulnerability and violence, which a lot of times contribute to the involvement of those young ones with the being. This article talks about the study of the Funk as process emancipator in measures socio-educational in CASE Santa Maria-RS, and he/she has as objectives understand the importance of the Funk as learning tool, to understand the processes of cultural expression, politics and social of the youths and to contribute for the effectiveness of the measures socio-educational. It is a Qualitative Research, using Method of approach dialectic and as technique the participant observation through project Reading's workshops, Action: Dramatization, accomplished in the year of 2018 with youths in measured socio-educational in it CASE Santa Maria/RS in the extent of the agreement among Federal University of Santa Maria, State Public prosecution service and Foundation of care socio-educational. The results observed in the development of the workshops were of the youths' recognition as political and social subjects and protagonists of his/her history, it gets better of the reading levels and construction of the knowledge and recognition of the Funk as cultural expression of their realities.
\end{abstract}

Keywords: Culture; Educação emancipadora; Funk; Measures socio-educational; Youth.

\title{
1. Introdução: adolescentes, medidas socioeducativas e a leitura
}

Relatar a experiência de ensino aprendizagem da leitura através do Funk é reportar-se ao contexto que será aqui discutido: adolescentes em cumprimento de medidas socioeducativas de internação e semiliberdade, desenvolvido no âmbito do convênio Universidade Federal de Santa Maria, Ministério Público Estadual e Fundação de Atendimento Socioeducativo mais especificamente no Centro de Atendimento Socioeducativo CASE-Santa Maria/RS, contexto que surge as ações que serão aqui discutidas e implementadas.

A Constituição da República Federativa do Brasil de 1988 e na Lei 8.069/90 eleva crianças e adolescentes à condição de sujeitos de direitos e os reconhece como pessoas em desenvolvimento, além de conferir à família, ao Estado e à sociedade o dever de assegurar seus direitos fundamentais e de proteção com prioridade absoluta (Art. 227, CF/88).

Conforme Hein (2018), as políticas públicas de prevenção à infração na adolescência tem sido tema de grande relevância, o ato infracional na adolescência pode acarretar consequências negativas tanto para os jovens como para seu ambiente. No Brasil, o adolescente que comete algum tipo de ato infracional fica submetido às medidas socioeducativas previstas no Estatuto da Criança e do Adolescente (ECA) Lei n. 8.069 (1990). 
Quanto ao cometimento de atos infracionais, o ECA (1990) define diretrizes para a responsabilização dos jovens por meio de medidas socioeducativas, sempre que o ato infracional for cometido antes dos 18 anos. Essas medidas podem ser cumpridas pelo adolescente tanto em liberdade (como no caso da advertência, da prestação de serviços à comunidade e da liberdade assistida) como em regime de internação (por um período máximo de três anos) Lei n. 8.069 (1990).

Devemos levar em conta que a adolescência, devido às diversas alterações psicossociais, com a busca por maior liberdade e autonomia, a influência da família começa a declinar. A família não perde sua função socializadora, mas as relações estabelecidas fora do reduto familiar, nesse período da vida, passam a ocupar uma posição de destaque. A escola e o grupo de pares passam, então, a se destacar enquanto instâncias de socialização, com maior possibilidade de influência sobre o comportamento dos adolescentes (PAPALIA; OLDS, 2000).

Portanto, pela circunstância da idade, o adolescente tem sua conduta considerada como ato infracional, sendo denominado no processo legal, de ato infracional e não criminoso ou contraventor a lei define sua condição especial de pessoa em desenvolvimento. $\mathrm{O}$ tratamento difere quanto à autoria de ato infracional. À criança são aplicadas as medidas de proteção, previstas no artigo 101 do ECA (1990); ao adolescente, as medidas socioeducativas, sem prejuízo das medidas de proteção.

Com esta compreensão as medidas socioeducativas foram propostas como instrumentos a serem aplicados aos adolescentes que praticaram ato infracional. Nesse sentido, é importante compreender que as medidas socioeducativas têm como proposta possibilitar um conjunto de condições que possam viabilizar ao adolescente, com base no respeito à sua condição de sujeito em desenvolvimento, à construção de um projeto de vida digna, com respeito à sua comunidade, protagonizando uma cidadania de convivência coletiva baseada no respeito mútuo.

As medidas socioeducativas previstas pelo ECA representam um procedimento especial, de caráter sancionatório-punitivo, com finalidade pedagógico-educativa, aplicada aos adolescentes autores de ato infracional considerados inimputáveis, em virtude da menoridade. Volpi (2001) trás que a medida socioeducativa é ao mesmo tempo, a sanção e a oportunidade de ressocialização, contendo, portanto, uma dimensão coercitiva, uma vez que o adolescente é obrigado a cumpri-la, e educativa, uma vez que seu objetivo não se reduz a punir o adolescente, mas prepará-lo para o convívio social. Desta forma a medida 
socioeducativa não pode ser neutra, ela evidencia-se quando se articula sujeito/ação x sujeito/saber.

Conforme Freire (1992), ler um texto é algo sério (...) é aprender como se dão as relações entre as palavras na composição do discurso. É tarefa de sujeito crítico, humilde e determinado. (...) Implica que o (a) leitor (a) se adentre na intimidade do texto para aprender sua mais profunda significação.

Neste propósito o Funk, como manifestação politica e sócio cultural dos jovens, colabora na eficácia das medidas e como recurso pedagógico de aprendizagem e ressocialização. O tema do funk como processo emancipatório nas medidas socioeducativas contribui para ampliação da discussão sobre educação, cultura, emancipação dos sujeitos e violência, ampliando o ensino aprendizagem da leitura através da expressão artística e cultural do funk.

Cabe nos perguntar como ampliar o processo ensino aprendizagem da leitura dos adolescentes em cumprimento de medidas socioeducativas de internação e semiliberdade, desenvolvido no âmbito do convênio Universidade Federal de Santa Maria, Ministério Público Estadual e Fundação de Atendimento? Como a leitura das músicas de Funk e podem contribuir com o processo de ensino aprendizagem e de ressocialização? Partindo destes pressupostos o objetivo deste trabalho é compreender a importância do Funk como ferramenta de aprendizagem entendendo assim os processos de expressão cultural, política e social dos jovens e contribuindo para a eficácia das medidas socioeducativas, no CASE de Santa MariaRS.

Nesse sentido, inserem-se os círculos de cultura como espaço de diálogos, onde o grupo compartilha compartilhar suas experiências e conhecimentos para melhorar o ensino aprendizagem da leitura com adolescentes que cumprem medidas socioeducativas. O Círculo de Cultura, proposto por Freire (2005), representa conceitualmente um espaço dinâmico, de caráter dialógico de aprendizagem e de troca mútua de conhecimentos, fundamentada na pedagogia libertadora e problematizadora proposta pelo teórico, onde todas as pessoas que o integram participam por meio do diálogo, leem, escrevem, discutem e constroem o mundo em que vivem.

É notório que o ensino aprendizagem da leitura do Funk através dos círculos de cultura estabelecido com os adolescentes agregam conhecimentos frente às ações previstas no projeto Institucional, rompendo contextos institucionalizados através os encontros realizados e desenvolvidos vem se realizando desde setembro de 2018 no CASE. 
Este processo inicialmente nos reportara ao contexto que surgem as inquietações que serão aqui discutidas, buscando responder questões que acompanham todo o processo de vivência: ensino aprendizagem da leitura? A música do Funk? Circulo de Cultura com adolescentes? Estes são os três pilares bases da proposta das ações junto ao Centro de atendimento Socioeducativo de Santa Maria - RS.

Portanto, acreditamos no ensino e aprendizagem da leitura como prática social voltada para a emancipação, onde os sujeitos (adolescentes) são protagonistas do processo educativo, assim o apoio pedagógico realizado pelo circulo de cultura, iniciando pela leitura da letra da música, da vida do cantor (MC) e visualização do clipe. Ao final, é discutido todo o processo realizado, bem como o seu registro, e definido o que será lido no próximo encontro são necessários para nossa ação pois, como em qualquer outro espaço educativo, deseja-se alcançar a aprendizagem dos sujeitos envolvidos.

Entendemos que as ações pedagógicas realizadas nos encontros constitui-se uma propostas realizada mediante diálogo nunca esquecendo dos princípios éticos , para não "invadir a privacidade do outro e expô-la aos demais" como mencionada Freire (1996).

Este estudo possibilita ouvir os sujeitos e suas histórias, conhecer as suas curiosidades, pois concordamos com Freire (1996) que é a curiosidade que faz "perguntar mais, conhecer, atuar, mais perguntar, reconhecer".

\section{Referencial Teórico}

Os Centros de Atendimento Socioeducativo são instituições que gerenciam as medidas socioeducativas de internação e semiliberdade, após a regulamentação no Estatuto da Criança e do Adolescente (1990). O objetivo dessas medidas é oferecer cuidados a esse adolescente, com atendimento psicossocial e com objetivo a educação, integração social e profissionalização deste adolescente na sociedade, respeitando seus direitos de adolescente. $\mathrm{O}$ ECA(1990) aponta no seu Art.124 direitos dos adolescentes privados de liberdade, destacando para esse artigo os incisos V"ser tratado com respeito e dignidade", XI "receber escolarização e profissionalização" e principalmente o inciso XII "realizar atividades culturais, esportivas e de lazer".

O Projeto Leitura, ação: dramatização surge num contexto de baixa escolaridade dos jovens internos das instituições da Fase-RS, pois a maioria entre 16 e 18 anos encontra-se aproximadamente no sexto e sétimo ano do ensino fundamental (FASE, 2018)

Diante de uma realidade de violência e vulnerabilidade, a escola para esses jovens acaba por tornar-se desinteressante, e a consequência disso é o abandono precoce dos estudos, 
baixos níveis de leitura e escolaridade, interpretação de texto, consciência histórica e política, e, o envolvimento desses jovens com o tráfico de entorpecentes.

A partir dos ensinamentos de Paulo Freire (2001) em que a leitura da palavra precede a leitura do mundo emergiu a necessidade da criação de oficinas de leituras no CASE Santa Maria-RS. Sendo a leitura um ato político, e também um direito previsto na Constituição Federal de 1988 e no Estatuto da Criança e do Adolescente, surge então à necessidade de através da leitura promover construção de conhecimento, cultura, lazer e novas perspectivas para esses sujeitos.

O objetivo inicial do grupo de leitura era ampliar os níveis de leitura dos jovens a partir de assuntos e temas que fizessem parte do cotidiano dos meninos e que fosse do interesse dos mesmos. Portanto, desde setembro de 2018 a oficina acontece uma vez por semana no CASE/SM e no Casemi/SM, sendo em média 5 a 10 participantes, sempre os mesmos.

Num primeiro momento de apresentação e conversa sobre nossos costumes e particularidades, facilmente o Funk mostrou-se como tema interessante para os meninos do grupo. Nesse sentido, a oficina foi construída coletivamente, utilizando a metodologia dos círculos de cultura de Freire (1998) que consiste no aprendizado em círculos, fomentando a participação máxima dos educandos desde a formação do cronograma das atividades, assim como no debate, para que se possa construir um debate democrático e horizontal. A oficina de Leitura desde então passou a ser chamada de Oficina de Funk, pois a leitura da história do Funk, das letras de músicas de Funk, da biografia dos Mcs virou rotina na oficina de Leitura.

O aprendizado do Funk, das histórias de vida dos MCs, do discurso apontado nas letras possibilitou a desconstrução de estigmas do senso comum sobre esse estilo musical. O Funk, conforme aponta Laignier (2013), mais do que um discurso sexualizado e de apologia ao crime, é principalmente o objeto da fala dos sujeitos das periferias brasileiras. É um artifício utilizado para dar voz a esses indivíduos, e oportunidade de falar sobre os problemas que encontram, sobre seus sonhos, seus anseios, sobre sua visão de mundo, etc.

Portanto, considerando a situação de vulnerabilidade, violência, violação de direitos como educação, saúde, cultura, moradia, e inúmeros outros, o Funk surge como uma nova perspectiva para os adolescentes da periferia, de obter educação, lazer, cultura, e condições de sobrevivência, direitos que para esses sujeitos são negados. É a oportunidade de dar voz a um público que tem o que dizer, tem suas particularidades, que precisa e deve reivindicar direitos negados, e que muitas vezes, é invisibilizada e estigmatizada pela sociedade.

A leitura e discussão da biografia e letras dos Mcs como Mc Menor da Mr, Mc 
Rodson, Mc Daleste, Mc Tikão, Mc Magal, entre outros, possibilitou a discussão e problematização de temas como drogas, sexo, pobreza, família, sonhos, amor, trabalho, dinheiro, e apresentou para os meninos novas perspectivas de vida, observando a realidade desses MCs que são da periferia, viveram em extrema vulnerabilidade, e encontraram no Funk uma ferramenta de representar a sua comunidade, e evitar destinos como o envolvimento com o crime, a prisão ou até a morte.

O estudo do Funk inaugurou reflexões sobre a realidade da maioria dos adolescentes em medida socioeducativa, como o afastamento e desinteresse com a escola, a pressão social que esses adolescentes sofrem dentro de uma sociedade capitalista que exclui quem não pode consumir, a vivência em estruturas familiares fragilizadas, envolvimento de parentes com uso de drogas, tráfico e outros crimes, contato com armas, drogas, crimes desde cedo da infância. Esses fatores, segundo Rolim (2014) são determinantes para a formação de jovens violentos, consequentemente envolvendo-se com o crime.

Tratamos de uma dinâmica pela qual meninos pobres são introduzidos em lógicas extremamente violentas a partir da influência exercida por outros indivíduos mais velhos e detentores de habilidades e valores particulares. Esse processo de socialização primária é exercido nas comunidades menores por traficantes e talvez se constitua no problema mais urgente e mais sério a ser enfrentado se tivermos em conta as dinâmicas sociais que agenciam sistematicamente a violência. (ROLIM, 2014, p. 208)

Este processo de trabalho parte dos princípios educativos pedagógicos do papel do educador de que: "ninguém educa ninguém, como tampouco ninguém se educa a si mesmo: os homens se educam em comunhão, mediatizados pelo mundo" (FREIRE, 1987, p. 79). Assim entendemos cada encontro nos Círculos de Cultura efetivados o respeito e reconhecimento que nós como educadoras devemos manter para com os adolescentes (educando) reconhecimento dos saberes que eles possuem, através da relação o diálogo, numa conversa entre onde trocamos saberes e conhecimento.

Assim Freire explicita a importância da práxis reflexiva, a reflexão permanente do processo, ação-reflexão-ação (TORRES, 1987). A elaboração do processo somente acontece com a análise sobre as atividades e refletindo sobre os caminhos percorridos. A construção do processo, porque em conjunto com os adolescentes, propomos relações dialógicas e dialéticas, sempre apresentando situações inusitadas ou incomuns. Isto é benéfico e promissor, já que a finalidade da educação Freireana é questionar as relações sociais, identificar as opressões e supera-las.

\section{A metodologia utilizada para ensino aprendizagem da leitura através do FUNK.}


Este estudo é definido como qualitativo, utilizando-se dos princípios da abordagem Dialético, e da técnica de levantamentos de dados, a observação participante. Através das oficinas do Projeto Leitura, Ação: Dramatização realizada a mediante os Círculos de Cultura, com jovens em medidas socioeducativa privados de liberdade e semiaberto no CASE Santa Maria/RS, no âmbito do convênio entre Universidade Federal de Santa Maria, Ministério Público Estadual e Fundação de Atendimento Socioeducativo.

A pesquisa é qualitativa conforme Marconi \& Lakatos (2008) é um método que difere da quantitativa pela forma de coleta e análise dos dados, preocupa-se em analisar e interpretar aspectos mais profundos, descrevendo a complexidade do comportamento humano, fornece análise mais detalhada sobre as investigações, hábitos, atitudes e tendências de comportamento, evidenciados nos encontros semanais com os adolescentes.

A abordagem dialética segundo Lakatos e Marconi (2008) fundamenta-se nas leis da dialética onde o mundo não pode ser entendido como um conjunto de "coisas", mas como um conjunto de processos, em que as coisas estão em constante mudança, sempre em vias de se transformar. As coisas e os acontecimentos existem como um todo, ligados entre si, dependentes uns dos outros.

Em síntese, o método dialético parte da premissa de que, na natureza, tudo se relaciona, transforma-se e há sempre uma contradição inerente a cada fenômeno. Nesse tipo de método, para conhecer determinado situação necessitamos entender todos os aspectos que envolve fenômeno estudado, precisamos compreender todos os seus aspectos, suas relações e conexões, neste estudo a realidade sócio, cultural política dos adolescentes e que mediante a realização do os círculos de cultura e do ensino aprendizagem da música de Funk expressam esta realidade.

Concordamos com Martins (1996) ao utilizarmos a observação participante estamos também em constante aprendizagem, compreendendo e intervindo no contexto em que estamos atuando, sendo a observação parte no meio onde estamos envolvidos, proporcionando uma aproximação ao quotidiano dos indivíduos e das suas representações sociais, da sua dimensão histórica, sociocultural, dos seus processos. Por outro lado, permitelhe intervir nesse mesmo quotidiano, e nele trabalhar ao nível das representações sociais, e propiciar a emergência de novas necessidades para os indivíduos que ali desenvolvem as suas atividades.

Assim definimos como ação dos encontros realizados semanalmente os Círculos de Cultura, onde definiu-se o Funk como tema gerador deste processo. Os círculos de cultura sistematizados por Paulo Freire (1991) estão fundamentados em uma proposta pedagógica, 
cujo caráter propõe uma aprendizagem integral, que rompe com a fragmentação e requer uma tomada de posição perante os problemas vivenciados em determinado contexto.

As atividades são realizadas em forma de círculo, iniciando pela leitura da letra da música, da vida do cantor (MC) e visualização do clipe. Ao final, é discutido todo o processo realizado, bem como o seu registro, e definido o que será lido no próximo encontro. Portanto esta metodologia permite realizar o processo de ensino aprendizagem da leitura através do FUNK e apresentar os resultados encontrados neste processo

\section{Resultados obtidos: Primeiro Comando da Paz}

O primeiro resultado observado e esperado no andamento das oficinas é o aumento dos níveis de leitura e interpretação dos adolescentes. A partir do momento que a leitura é de temas que são interessantes para esses sujeitos, é mais fácil desenvolver o hábito de leitura, e consequentemente, aprendizado, aumento do vocabulário, reflexões, nova visão de homem e de mundo.

A formação de uma consciência de pertencimento a um grupo, de coletividade, criação de vínculos, criação de uma relação horizontal de respeito mútuo, também é um resultado gratificante obtido nas oficinas. Com o objetivo de potencializar essa identidade de grupo, criamos um nome para o grupo, utilizando como base o prefixo "Comando" utilizado nos nomes de facções, porém, com outro significado, criamos o Primeiro Comando da Paz. É visível o comprometimento dos integrantes do grupo com os encontros, com a realização das atividades propostas e com os prazos determinados.

A oficina me mostrou que o Funk não é só apologia, que cada funkeiro já passou por algo ruim na vida. E adoro a convivência com as professoras, são geniais, pacientes, e bem gentis com nós. Aprendi a interagir mais, ler melhor, etc. (Relato de um dos integrantes do grupo).

O estudo do Funk possibilitou a reflexão das vivências pessoais e dos ciclos de vida que cada um do grupo se encontrava (antes da medida socioeducativa, como está sendo durante o período, quais as perspectivas para após o término da medida), assim como descoberta de potencialidades, de áreas do conhecimento que mais se identificam, de ler sobre a história dos MCs e reconhecer-se nessa realidade e perceber novas perspectivas para sua vida.

De modo geral, considerando o momento da adolescência, o contexto social que esses meninos se encontram, a não identificação com leitura e baixa escolaridade dos meninos, os 
resultados têm sido surpreendentes. O Funk é um instrumento de fala, de reflexão, de lazer, de cultura, de denuncia, de sobrevivência, e também, de educação.

\section{Considerações necessárias: lendo o mundo através da música do Funk.}

Baseado no trabalho desenvolvido através das oficinas do Projeto Leitura, ação: Dramatização, conclui-se que o Funk é uma ferramenta de emancipação dos indivíduos, tanto os que escutam como os que compõem, os que produzem, e até, no caso deste artigo, os que o utilizam como ferramenta de educação.

Nesse sentido, este artigo contribui para potencializar as eficácias das medidas socioeducativas, bem como ser útil para a reprodução da metodologia de ensino em outras situações, sejam através do Funk em outras instituições de ensino, sejam através da leitura em outras instituições de medidas socioeducativas.

Nota-se, por fim, que o estudo do Funk, a oportunidade de ler, de aprender, de conhecer novas perspectivas, contribui para a formação de sujeitos políticos e sociais, com pensamento crítico, com objetivos, conscientes dos seus direitos, e mais preparados para exercerem a cidadania que lhes foi negada.

Por último, pretendemos potencializar as oficinas, trazendo outros assuntos importantes que precisam ser problematizados como raça, gênero, família, redução de danos, entre outros, para que o trabalho através da leitura do Funk continue gerando bons resultados.

\section{Referências}

BRASIL. Estatuto da Criança e do Adolescente, Câmera dos Deputados, Lei no 8.069, de 13 de julho de 1990. DOU de 16/07/1990 - ECA. Brasília, DF.

BRASIL. Constituição da República Federativa do Brasil. Presidência da República. 5 de outubro de 1988. Brasília, DF

FASE. Dados estatísticos. 2018 Disponível em http://www.fase.rs.gov.br/wp/dados_estatisticos/> Acesso em 12 de dezembro de 2018

FREIRE, Paulo. A Educação na Cidade. São Paulo: Cortez, 1991.

FREIRE, Paulo. A importância do ato de ler: em três artigos que se completam. 23 ed. São Paulo: Editora Cortez, 1989.

FREIRE, Paulo; BETTTO, Frei. Essa Escola Chamada Vida: Depoimentos ao repórter 
Ricardo Kotscho. 9 ed. São Paulo: Editora Ática, 1998. 95 p.

FREIRE, Paulo. Pedagogia da Autonomia. 39a. ed. São Paulo: Paz e Terra, 1996.

FREIRE, Paulo. Pedagogia do oprimido. 13. ed. Rio de Janeiro: Paz e Terra, 1987.

HEIN, A. Factores de riesgo y deincuencia juvenil: revision de la literatura nacional e internacional. Santiago. Fundação Paz e Cidadania. Acesso: 15 dez. 2018. Disponível em <https://s3.amazonaws.com/academia.edu.documents/34713405/FACTORES_DE_RIESGO DE_LA_DELINCUENCIA_JUVENIL Factores_de_riesgo_y_deincuencia_juvenil.pdf.> Acesso em 08 de Janeiro de 2018

LAIGNIER, Pablo. Do funk fluminense ao funk nacional: o grito comunicacional das favelas e subúrbios do Rio de Janeiro. 2013. Tese (Programa de Pós-graduação em Comunicação) Escola de Comunicação, Universidade Federal do Rio de Janeiro, Rio de Janeiro.

MARTINS, J. B. Observação Participante: uma abordagem metodológica para a Psicologia Escolar. Seminário Ciências Sociais / Humana. 1996.

MARCONI, M. A., LAKATOS, E. M. Metodologia Científica. 5. ed. 2. São Paulo: Atlas, 2008.

PAPALIA, E. D; OLDS, W. S. Desenvolvimento Humano. 7 ed. Porto Alegre: ArtMed, 2000.

ROLIM, Marcos. A formação de jovens violentos: para uma etiologia da disposicionalidade violenta. 2014. Tese (Programa de Pós-graduação em Sociologia) - Instituto de Filosofia e Ciências Humanas, Universidade Federal do Rio Grande do Sul, Porto Alegre.

TORRES, R. M. Educação Popular, um encontro com Paulo Freire. São Paulo. Edições Loyola, 1987.

VOLPI, Mário (org.). O adolescente e o ato infracional. 4 ed. São Paulo: Cortez, 2002. 